\title{
LEITURA E DESEMPENHO ESCOLAR DE ALUNOS DO ENSINO FUNDAMENTAL
}

\author{
READING AND SCHOOL PERFORMANCE \\ OF ELEMENTARY SCHOOL STUDENTS \\ LECTURA Y DESEMPEÑO ESCOLAR DE ALUMNOS \\ DE ENSEÑANZA PRIMARIA
}

Subvenção CNPQ

Andreia Osti ${ }^{\mathrm{I}}$

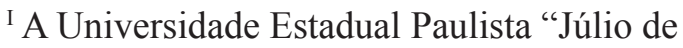
Mesquita Filho" (UNESP),

Rio Claro/SP-Brasil

RESUmo Este trabalho se dedica a identificar a rotina de leitura de alunos e compará-la com o desempenho escolar. A pesquisa é de natureza quali-quantitativa e dela participaram 100 estudantes do $5^{\circ}$. ano do Ensino Fundamental, de seis escolas públicas municipais de uma cidade no interior de São Paulo. Para avaliar o contexto leitor foi construído um questionário, que buscou conhecer quais gêneros textuais os alunos estão lendo, quais pessoas foram o seu principal modelo leitor e qual a frequência de leitura. Em relação ao desempenho escolar, foram coletadas as notas dos estudantes na disciplina de Língua Portuguesa junto à coordenação da escola. A maioria dos estudantes enfatizou que a leitura é importante para a aprendizagem e se configura como uma atividade interessante, no entanto admitem que preferem acessar as redes sociais ao invés de ler um livro. Em relação ao desempenho, os alunos com notas satisfatórias realizam leituras com maior frequência, quando comparados aos alunos com notas insatisfatórias. Os últimos afirmam que a leitura, muitas vezes, representa uma obrigação e não um prazer. Entende-se que esse resultado pode ser consequência da dificuldade de os estudantes em ler, uma vez que os mesmos apresentam desempenho abaixo do esperado, sobretudo na disciplina de Língua Portuguesa. Tais dados permitem discutir sobre a importância do incentivo à leitura e a respeito do trabalho com os diferentes gêneros textuais na escola. Também evidenciam que maior acesso a diferentes fontes de leitura pode ser fator que implica diretamente a questão do desempenho escolar, influenciando a diversidade entre os grupos.

Palavras-chave: Rendimento escolar; Ensino; Leitura. 
ABSTRACT This work is dedicated to identify the student reading routine and comparing it with school performance. The research is of a qualitative nature and was attended by 100 students from the 5th grade of elementary school, from six public municipal schools of a city in the interior of São Paulo. To evaluate the reader context, a questionnaire was constructed that sought to know which textual genres students are reading, which people were their main reader model and how often they read. In relation to the school performance, students' scores in the Portuguese Language course were collected along with the coordination of the school. Most students emphasized that reading is important for learning and configures an interesting activity, however they admit that they prefer to access social networks rather than reading a book. Regarding performance, students with satisfactory performance perform readings more frequently when compared to students with poor performance. The latter state that reading is often a duty rather than a pleasure. It is understood that this result may be a consequence of the students' difficulty in reading, since they perform poorly, especially in the Portuguese Language course. These data allow us to discuss the importance of encouraging reading and working with the different textual genres in school. They also show that greater access to different sources of reading may be a factor that directly implies the issue of school performance, influencing the difference between the groups.

Keywords: School income; Teaching; ReAding.

ReSumen Este trabajo se dedica a identificar la rutina de lectura de alumnos y compararlo con el desempeño escolar. La investigación es de naturaleza cualitativa y de ella participaron 100 estudiantes del $5^{\circ}$. año de la enseñanza fundamental, de seis escuelas públicas municipales de una ciudad en el interior de São Paulo. Para evaluar el contexto lector fue construido un cuestionario que buscó conocer qué géneros textuales los alumnos están leyendo, cuáles personas fueron su principal modelo lector y cuál es la frecuencia de lectura. En relación con el rendimiento escolar, se recogieron las puntuaciones de los estudiantes en la disciplina portugués por la escuela de coordinación. La mayoría de los estudiantes enfatizó que la lectura es importante para el aprendizaje y configura una actividad interesante, sin embargo admite que prefieren acceder a las redes sociales en lugar de leer un libro. En relación al desempeño, los alumnos con calificaciones satisfactorias realizan lecturas con mayor frecuencia, en comparación con los alumnos con una calificaciones insatisfactorias. Estos últimos afirman que la lectura a menudo representa una obligación y no un placer. Se entiende que este resultado puede ser una consecuencia de la dificultad de los estudiantes a leer, ya que muestran un rendimiento deficiente, sobre todo en la disciplina de la Lengua Portuguesa. Tales datos permiten discutir sobre la importancia del incentivo a la lectura y el trabajo con los diferentes géneros textuales en la escuela. También evidencian que mayor acceso a diferentes fuentes de lectura puede ser factor que implica directamente en la cuestión del desempeño escolar, influenciando la diferencia entre los grupos.

Palabras clave: Rendimiento escolar; Educación; La lectura. 


\section{INTRODUÇÃo}

Saber ler é condição indispensável para que todos os cidadãos possam adquirir conhecimentos, ter plena participação social, propriedade de seus direitos, deveres e, principalmente, acesso à cultura letrada. Apesar dessa assertiva, sabe-se que o Brasil ainda amarga em sua história o fracasso de inúmeros alunos que saem da escola sem estarem alfabetizados e, quando saem, não têm pleno domínio da leitura e da escrita. De acordo com os dados da Pesquisa Nacional por Amostra de Domicílios (PNAD, 2019), em 2018, a taxa de analfabetismo no Brasil foi de $6,8 \%$, o que representa um contingente de aproximadamente 11,3 milhões de pessoas. Em 2018, apenas 13 Estados atingiram a meta de redução do analfabetismo estipulada para o ano de 2015. O baixo índice contribuiu para que o Brasil até agora não tenha atingido a meta parcial de reduzir para $6,5 \%$ a taxa de analfabetismo. Em 2019, de acordo com o IBGE, esse número diminuiu para 6,6\%, com aproximadamente 11,041 milhões de pessoas que já completaram 15 anos de idade sem aprender a ler nem a escrever. Esses índices evidenciam que a aquisição da leitura e da escrita ainda é um problema social para grande parte da população brasileira, sobretudo para a população que depende da escola pública.

Em relação à leitura, de acordo com o Instituto Nacional de Estudos e Pesquisas Educacionais (INEP), que apresenta os resultados referentes à Prova Brasil de 2015, aplicada aos alunos do $5^{\circ}$. ano, somente $44 \%$ dos alunos do Estado de São Paulo atingiram os conhecimentos esperados no eixo leitura. Nos dados referentes a 2017, houve uma progressiva melhora nos resultados, uma vez que o índice de São Paulo passou de 6,4\%, em 2015, para $6,5 \%$, em 2017. Já nos anos finais do Fundamental ( $6^{\circ}$. ao $9^{\circ}$. ano), o Estado passou de $4,7 \%$, em 2015, para 4,8\%, em 2017. Mesmo que o INEP pontue um crescimento qualitativo das avaliações, constata-se que muitos alunos ainda estão distantes do esperado, uma vez que se constata que no $5^{\circ}$. ano de escolaridade, os estudantes brasileiros apresentam nível 4 de proficiência média, sabendo que os níveis 8 e 9 da Prova Brasil representam os níveis de avanço.

Mais recentemente, o Sistema Nacional de Avaliação da Educação Básica (SAEB, 2020) publicou os resultados do SAEB de 2019, em que os resultados dos anos iniciais foi o mesmo da edição de 2017 na avaliação de português enquanto o desempenho de unidades da Federação teve queda na variação da média dessa disciplina em 2019. A proficiência caiu em 12 Estados, no rendimento do $5^{\circ}$. ano; e em nove Estados, no $9^{\circ}$. ano. Em relação ao Ensino Médio, não houve queda no rendimento em língua portuguesa, mas 15 unidades não tiveram resultado igual ou maior que a média do país, de 278,4 pontos. Destaca-se que, no Ensino Médio, sete de cada dez estudantes têm nível insuficiente em português e que essa etapa da educação básica foi classificada como nível 2 de proficiência, o que significa que esses estudantes deixam a escola sem conseguir identificar a informação principal em uma reportagem. No ensino fundamental, apesar de haver um melhor resultado, ainda é uma média insuficiente, pois, segundo o Ministério da Educação, o resultado retrata que os estudantes aprenderam o básico em Língua Portuguesa. Em se tratando da leitura no Ensino Fundamental, afirma-se que os estudantes deixam o Ensino Fundamental com desempenho pior do que entraram. 
Mendonça e Aranha (2009) apontam que uma em cada dez crianças não sabe ler aos 11 anos de idade e que muitas delas passam despercebidas na escola. Afirmam ainda que, embora todos os alunos devam saber ler e escrever ao final do terceiro ano do Ensino Fundamental, muitos chegam ao sexto ano sem esse conhecimento. Esses dados conduzem a uma reflexão sobre o que os alunos das escolas públicas estão efetivamente aprendendo na escola, qual qualidade de ensino está sendo ofertada a essa população que fica na escola ao menos cinco anos e, muitas vezes, sai dela sem ao menos saber ler e escrever adequadamente? Apesar de essa situação ser grave, é comum em muitas escolas públicas de todo o país. É uma realidade que motiva a pesquisa e o debate em várias universidades bem como em diferentes instâncias do setor público.

Cabe também destacar que, segundo a Pesquisa Retratos da Leitura no Brasil (2020), realizada entre outubro de 2019 a janeiro de 2020, em 208 municípios, com 8.076 participantes, o índice de leitura da população brasileira ainda é baixo, uma vez que o brasileiro lê apenas 5 livros por ano, e, desses, apenas 2,5 foram lidos integralmente. As mulheres representam $54 \%$ dos leitores, e o índice de leitores está na faixa etária entre 18 e 24 anos e diminuiu de 67\%, em 2015, para 59\%, em 2019. Em consonância, o levantamento divulgado pelo Banco Mundial, com base em dados do Programa de Avaliação de Alunos (Pisa), indica que os estudantes brasileiros devem demorar mais de 260 anos para atingir a qualidade de leitura dos alunos de países desenvolvidos. Dessa forma, é evidente que o país tem um baixo índice de leitura, sendo a escola um local propício para o incentivo dessa atividade.

Nesse contexto, diversos autores (SOARES, 2016; 2004; GONTIJO, 2014; MORAIS, 2012; NEVES, 2011; FRADE, 2010) enfatizam a necessidade, na atualidade, de desenvolver habilidades de uso da leitura nas práticas sociais que envolvem a língua escrita e o reconhecimento de que sua aprendizagem exige múltiplas metodologias direcionadas tanto para o ensino direto e sistemático dos conteúdos, quanto para o ensino indireto, que possibilite, em sala de aula, motivar e instigar nos alunos a vontade e a necessidade de ler e escrever. Ainda nessa perspectiva, Santos (2015) afirma que o texto deve constituir instrumento central no processo de ensino e que os alunos devem ser direcionados a textos reais, coerentes e ricos de elementos coesivos. Desse modo, entende-se que a leitura precisa ser trabalhada na escola, como atividade didática e também como forma de desenvolver a prática cotidiana da leitura além do espaço escolar.

De acordo com Soares (2016), Morais (2015), Guedes e Souza (2011), ler e escrever são tarefas específicas e indissociáveis da vida escolar e, para Sforni e Galuch (2006), a formação da autonomia intelectual e do pensamento crítico dependem de uma sistematização do ensino, o que configura a importância do trabalho didático da leitura na escola. A leitura é entendida como uma atividade intencional em que uma pessoa, ao ler, não está meramente decodificando um código, mas está tendo compreensão, estabelecendo relações, formando opiniões e assimilando o que está sendo lido.

Mediante o exposto e assumindo a perspectiva de letramento (SOARES, 2004; 2006; 2016), considera-se que a escola de ensino fundamental necessita fomentar no educando a necessidade e o desejo pela leitura como modo de contribuir para a sua formação como estudante e como cidadão, despertando esse aluno para a importância de se inserir no mundo letrado como um sujeito que dialoga com o conhecimento cultural. Especificamente, no 
âmbito da sala de aula, o professor precisa ser modelo de leitura e oportunizar ao estudante o contato e a leitura de diferentes gêneros textuais. De acordo com Farias e Bortolanza (2017), a leitura é ato social que promove a interação verbal do sujeito com os outros e realiza um processo ativo de construção de significados a partir de sua relação com o contexto histórico e cultural em que está inserido, situado num espaço e tempo determinados. Dessa forma, a leitura se constrói e se concretiza em práticas sociais.

Entende-se, neste texto, que o domínio da leitura é essencial a todos os alunos da educação básica e que esse domínio implica um conjunto de habilidades que permitem ao indivíduo expressar suas opiniões, fundamentar seus argumentos bem como ter entendimento do que lê, conseguindo criticar e se posicionar frente à informação recebida. Ou seja, saber ler implica ter conhecimentos linguísticos, adquirir o sistema convencional de escrita e se utilizar desse sistema em práticas sociais, fazendo uso efetivo da leitura.

Nacionalmente, pode-se observar diversas ações governamentais, nas esferas estaduais e federais, que buscam junto às suas secretarias de educação formas de melhorar os índices da leitura entre os estudantes. As Diretrizes Curriculares Nacionais para a Educação Infantil (2009) enfatizam que as práticas de leitura devem assegurar a expressão e a ampliação da linguagem e o prazer pelo aprender, reconhecendo a criança como ativa e criadora da cultura. O Pacto Nacional pela Alfabetização na Idade Certa - PNAIC (2013), implementado em 2012, procurou garantir o direito à alfabetização plena a todas as crianças de 8 anos de idade. Em seus princípios centrais, apresenta um ponto que consideramos fundamental em nossa análise: o desenvolvimento das capacidades de leitura e de produção de textos ocorre durante todo o processo de escolarização, mas deve ser iniciado logo no início da Educação Básica, garantindo acesso precoce a gêneros discursivos de circulação social e a situações de interação em que as crianças se reconheçam como protagonistas de suas próprias histórias.

Mais recentemente, a Base Nacional Comum Curricular (BRASIL, 2018) define o fim do ciclo de alfabetização no segundo ano do ensino fundamental e preconiza, no que diz respeito à área de Linguagens, que a mesma é composta por quatro subáreas: Leitura, Escrita, Oralidade e Conhecimento sobre a Língua e a norma. A primeira e a terceira, especificamente, compreendem o trabalho com diferentes modalidades de gêneros textuais que têm por função a ampliação do vocabulário e o desenvolvimento de habilidades e estratégias de leitura bem como as relações entre fala e escrita e a produção de gêneros orais. Observando essa organização, pode-se inferir que aos alunos das séries iniciais serão oferecidas atividades variadas de leitura, o que irá oportunizar uma ampla formação leitora.

Já o Decreto $\mathrm{n}^{\circ}$. 9.765, de 11 de abril de 2019, que institui a Política Nacional de Alfabetização, define como diretriz a priorização da alfabetização no primeiro ano do ensino fundamental, ou seja, as últimas políticas públicas estão fixando o período para a alfabetização entre os dois primeiros anos do ensino fundamental, o que direciona a uma nova organização da escola voltada diretamente para o ensino da leitura e da escrita com a finalidade de melhorar a qualidade da alfabetização no território nacional.

De acordo com Kramer (2010), a formação de leitores deve assegurar formação cultural, formação do gosto e leitura literária. Também destaca que é direito da criança o convívio com a literatura infantil e com a cultura letrada, garantindo a criação, a imaginação e a 
expressão. Em consonância, Soares (2006), Frade (2007), Batista (2012) e Gontijo (2014) esclarecem que o aluno precisa ser efetivamente inserido na cultura da linguagem escrita e oral, mas, para isso ocorrer, há um longo caminho a ser percorrido em todas as etapas da educação básica, principalmente na Educação Infantil e no Ensino Fundamental. Essa assertiva reforça a importância do trabalho diferenciado em sala de aula e reafirma a ideia de que o envolvimento com a leitura corresponde a um comportamento cultural, e para isso as crianças necessitam de modelos de leitores.

Pesquisadores envolvidos com área da leitura e escrita, (SOARES, 2016; GONTIJO, 2014; BAPTISTA, 2010; KRAMER, 2010; KISHIMOTO, 2010) vêm enfatizando que a escola precisa assumir a formação leitora de alunos como uma atividade essencial à formação desse alunado e que sejam criados momentos em que os estudantes sejam expostos e que tenham livre acesso aos livros e a todo material de leitura. O discurso oficial também se ancora no compromisso atribuído aos professores em formar alunos leitores e escritores. Os documentos e programas oficiais (PNAIC, 2013; SÃO PAULO, 2008; 2013; PRÓ-LETRAMENTO, 2008) preconizam que, ao final do $5^{\circ}$. ano do Ensino Fundamental, os alunos devem ser capazes de ler textos de diferentes gêneros e áreas do conhecimento e produzir textos de autoria, considerando as questões de textualidade (coerência, coesão, inclusive pontuação). Nesse contexto, é fundamental assegurar acesso a crianças e a adultos às narrativas, às músicas, aos desenhos, às peças teatrais, à dança e às mais diversas formas de expressão literária (acalantos, trava-línguas, provérbios, fábulas, contos, mitos, lendas, romances (KRAMER, 2010).

No entanto, Gontijo (2014) alerta que, apesar de essa assertiva estar muito clara no universo escolar, ocorre que muitos dos textos que têm sido privilegiados são parlendas, versos, listas, entre outros, que ajudam no processo de alfabetização por serem ricos em rimas e repetições de palavras, mas que não são os únicos que circulam na sociedade. Em consonância, Koch e Elias (2014) consideram que o ensino da leitura deve pôr em foco o leitor com seus conhecimentos em interação com o autor e o texto, para a construção de sentido. Sales (2007) afirma que urge repensar e reconstruir uma sociedade de leitores e não ledores e que, sendo a sala de aula o foco desse propósito, no professor recai, também, a tarefa de criar o ambiente favorável para emergir o gosto pela leitura.

Considera-se que, para a escola conseguir tornar o aluno leitor, são necessárias algumas ações pontuais, tais como: vivenciar práticas de leitura em diferentes momentos e em situações intra e extrassala de aula; propiciar o contato com diferentes gêneros textuais escritos, oportunizar situações de leitura, criar momentos na escola que envolvam diferentes disciplinas e conteúdos, em que a leitura seja uma atividade coletiva, entre outras. Para Batista (2012), a convivência social exige usar a variedade linguística em várias situações e, para isso, a escola deve desenvolver essa capacidade a partir de propostas lúdicas e de atividades diversificadas. Em se tratando especificamente da formação do leitor, Vieira, Fernandes, Silva e Martins (2008) enfatizam que o aluno precisa aprender a reconhecer e a classificar os diversos suportes da escrita, identificar as finalidades e as funções da leitura de alguns textos a partir do exame de seus suportes e a relacionar esse suporte às possibilidades de significação do texto. Também enfatizam que a leitura deve ser planejada como atividade cotidiana, não só entre alunos, mas também entre os professores. 
Sabe-se que a formação de leitores depende muito da relação que se estabelece entre o leitor e o conteúdo a ser lido. Nesse sentido, Vieira, Fernandes, Silva e Martins (2008) consideram que o incentivo à leitura é um trabalho complexo e depende da realidade da turma, mas é uma atividade que carece estar inserida no planejamento do professor. Lajolo e Zilberman (1986) apontam como preocupante o fato de muitos alunos não conhecerem a maioria das obras da literatura infantil brasileira e o fato de uma minoria de os estudantes brasileiros do ensino fundamental lerem por interesse ou gosto e a maioria para cumprir obrigações escolares (BRASIL, 2015). Ainda refletindo sobre a formação do leitor, no material do Pró-Letramento do Ministério da Educação (2008), é indicado que o aluno desenvolva uma série de capacidades linguísticas que precisam ser ensinadas sistematicamente. Entre as capacidades esperadas, podemos destacar no contexto da leitura: identificar diferenças entre gêneros textuais e localizar informações em textos de diferentes gêneros.

Especificamente no Estado de São Paulo, em termos das práticas de leitura, nas Orientações Curriculares (2008), há o entendimento de que o desenvolvimento da competência de ler é um processo que se prolonga por toda a vida, com a crescente participação nas práticas que envolvem a língua escrita e que se traduz na competência de ler e de produzir textos dos mais variados gêneros. Nesse documento, pode-se observar, no quadro de avaliação das aprendizagens, que as situações propostas nas atividades para o professor realizar em sala de aula, em relação à leitura, são praticamente as mesmas em todas as séries iniciais do Ensino Fundamental, isso porque parte-se do princípio de que a avaliação é um processo contínuo e, que em termos de conteúdo, se deve variar a complexidade do que é abordado e o grau de expectativa, ou seja, todos os alunos, em todas as séries do Ensino Fundamental, terão contato com os mesmas atividades.

Em relação às expectativas sobre o que o aluno seja capaz de aprender, pode-se afirmar, com base nas Orientações Curriculares (2008), que o mesmo saiba: apreciar textos literários, selecionar textos de acordo com os propósitos de sua leitura, sabendo antecipar a natureza de seu conteúdo, reescrever ou produzir textos de autoria, utilizando procedimentos de escritor, revistar textos, utilizar recursos para compreender ou superar dificuldades de compreensão durante a leitura, entre outros. Na Avaliação da Aprendizagem em Processo (SÃO PAULO, 2014), estão elencados os gêneros textuais que serão trabalhados por ano escolar, da seguinte forma: conto ( $6^{\circ}$. ano), relato de experiência vivida $\left(7^{\circ}\right.$. ano), notícia ( $8^{\circ}$. ano) e texto de opinião ( $9^{\circ}$. ano). Para as séries iniciais do Ensino Fundamental, as Orientações Curriculares do Estado de São Paulo (2008) explicitam que, ao longo de todas as séries do ciclo (do $1^{\circ}$. ao $5^{\circ}$. ano), serão realizadas leituras diárias de contos, lendas, mitos e livros de história em capítulos, bem como a leitura de diferentes gêneros textuais. Já nas Orientações Curriculares e Proposições de Expectativas de Aprendizagem para o Ensino Fundamental Ciclo I (SÃO PAULO, 2007), estão claramente definidas em cada um dos anos escolares o que deve ser trabalhado em sala de aula, segundo as diferentes esferas de circulação de textos (cotidiana, escolar, jornalística e literária). Assim, no $1^{\circ}$. ano, concentram-se atividades que envolvam receitas, listas, cartas, verbete de curiosidades, verbete de enciclopédia infantil, manchete, notícia, conto tradicional, literatura infantil, cantiga, trava-língua, adivinha, trova. 
No $2^{\circ}$. ano, inserem-se regras de jogo, bilhete, diagrama, legenda, conto de repetição, conto acumulativo, poema para crianças, parlenda. $\mathrm{O} 3^{\circ}$. ano foca o trabalho com carta/e-mail, verbete de curiosidades, artigo de divulgação científica, manchete, entrevista, reportagem, fábula, lenda, poema narrativo, cantiga tradicional, canção, explicação, notícia. No $4^{\circ}$. ano, temos: roteiro, mapa de localização, regras de jogo, verbete de enciclopédia virtual, artigo de divulgação científica para crianças, notícia, reportagem, lenda, mito, conto tradicional, literatura infanto-juvenil, poema, canções e relato de experiências vividas. Por fim, no $5^{\circ}$. ano, insere-se cordel, roteiro e mapa de localização/descrição de itinerário, notícia/ relato de acontecimentos do cotidiano, poema, além dos gêneros já descritos nos outros anos. Ou seja, é explícito na orientação didática que o professor irá trabalhar com vários gêneros textuais com o objetivo de fomentar a leitura de seus alunos e que esse trabalho diversificado será aprofundado progressivamente, ao longo de todo o ensino fundamental. Também está claro que, a cada ano do ciclo, serão exploradas basicamente as mesmas expectativas de aprendizagem, mas em graus de complexidade crescentes.

Essas informações indicam que os alunos do ensino fundamental, de maneira geral, terão durante sua escolarização contato com os mais diversos gêneros textuais e, pressupõe-se, que o professor fará a leitura de textos literários em vários momentos no cotidiano de seu trabalho. Tomando por base esses documentos que afirmam que, desde o primeiro ano, o ensino da Língua Portuguesa deve garantir que os alunos leiam diferentes textos e diversos gêneros, esse trabalho parte do pressuposto de que os estudantes foram apresentados a essa variedade textual, e que eles têm em sua trajetória escolar uma rotina de leitura realizada em sala de aula pelo professor, pelos próprios alunos, bem como contato com a biblioteca. Considera-se que, se o aluno não tem em casa o contato direto com a leitura, será a escola, segundo o currículo proposto nos documentos oficiais, que irá proporcionar esse conhecimento.

Nesse contexto, este trabalho se dedica a analisar a diferença no desempenho escolar em função da prática de leitura. Entende-se por prática de leitura a experiência do aluno com a leitura em diferentes situações de vida. Buscou-se conhecer quais gêneros textuais os alunos estão lendo, quais pessoas foram o seu principal modelo leitor e qual a frequência de leitura. Também se investigou a relação entre desempenho e leitura e a quais materiais de leitura os alunos têm acesso. Esclarece-se que os recursos materiais de leitura são entendidos como um conjunto de materiais específicos destinados à mesma, tal como livros de diferentes gêneros, jornais, quadrinhos e revistas. Aqui, neste texto, se reitera que é preciso conhecer os alunos que estão no Ensino Fundamental, quais suas fontes de leitura, diagnosticar suas dificuldades e identificar suas necessidades para que se possa efetivamente aprender na escola e sair dela com um repertório que possibilite a eles exercer e participar do universo da leitura.

\section{Procedimentos Metodológicos}

\section{Participantes}

Participaram da pesquisa 100 estudantes, de ambos os sexos, do $5^{\circ}$. ano do Ensino Fundamental, de seis escolas públicas municipais de uma cidade no interior de São Paulo. 


\section{Instrumentos}

Para avaliar o perfil leitor, foi construído um questionário com dezessete questões. As questões versavam especificamente sobre: a) qual o gênero textual mais lido pelo aluno; b) qual sua motivação e significado da leitura; c) qual a frequência de leitura realizada; d) quem são os adultos modelos leitores; e) conhecer como os alunos avaliam a sua própria leitura. Em relação ao desempenho escolar, foram coletadas as notas dos estudantes na disciplina de Língua Portuguesa junto à coordenação da escola. As notas foram classificadas da seguinte forma: desempenho satisfatório (quando dentro da média ou acima da mesma), desempenho insatisfatório (quando abaixo da média).

\section{Procedimento de coleta}

A pesquisadora apresentou a pesquisa nas unidades escolares junto a todos os estudantes em sala de aula, convidando-os a participar. Aqueles que aceitaram participar levaram para casa um comunicado aos pais e responsáveis, explicando sobre o que seria feito e os convidando a conversar com a pesquisadora pessoalmente na própria escola durante o período destinado à reunião de pais do primeiro semestre. No dia da reunião, a pesquisadora explicou aos pais e/ou responsáveis os objetivos da pesquisa, esclareceu sobre dúvidas e solicitou a assinatura em duas vias do Termo de Consentimento Livre e Esclarecido desses pais e/ou responsáveis. Apenas foram chamados para participar da pesquisa os estudantes autorizados por seus pais e que também concordaram e assinaram o Termo de Assentimento. A pesquisa foi realizada tendo a aprovação do Comitê de Ética em Pesquisa da Universidade Estadual Paulista - UNESP, respeitando-se o que preconiza a Resolução 510/16.

\section{RESUlTAdos E DISCUSSÃo}

A análise indica que $75 \%$ dos alunos apresentam idade compatível com a série e apenas $25 \%$ têm defasagem, tendo esse número de alunos histórico de repetência. No entanto, ao analisar mais especificamente o desempenho dos estudantes, mediante as notas em Língua Portuguesa, temos $61 \%$ de estudantes com desempenho satisfatório e 39\% com desempenho insatisfatório.

Destaca-se que, para facilitar a leitura das tabelas e no corpo do texto, a partir de agora, os grupos são nomeados da seguinte forma: alunos com desempenho satisfatório (DS) e alunos com desempenho insatisfatório (DI). O Quadro 1 descreve qual é o gênero textual mais lido pelos grupos, qual sua motivação, significado e frequência da leitura. 
Quadro 1 - Perfil leitor.

\begin{tabular}{l|l|l}
\hline \multicolumn{1}{c|}{ Categorias } & DS (\%) & \multicolumn{1}{c}{ Alunos } \\
\hline Principais leituras: & 40 & 38 \\
Livros didáticos & 11 & 36 \\
Histórias em quadrinhos & 36 & 05 \\
Romance / Literatura infantil & 13 & 21 \\
Piadas/ tirinha/ propaganda & & \\
Motivação para a leitura: & 37 & 22 \\
Atualização /conhecimento & 42 & 14 \\
Necessidade própria / prazer & 21 & 64 \\
Exigência da escola & & \\
& 30 & 12 \\
Significado da leitura: & 63 & 09 \\
Fonte de conhecimento & 07 & 79 \\
Prazer e divertimento & & \\
Obrigação e esforço & 25 & 58 \\
& 47 & 33 \\
Frequência da leitura de livros: & 28 & 09 \\
01 livro por ano & & \\
De 02 a 05 livros por ano & & \\
Mais de 05 livros por ano & & \\
\hline
\end{tabular}

Fonte: Dados da pesquisa.

Em relação aos gêneros lidos, percebe-se que os livros didáticos são lidos por ambos os grupos, muito em decorrência da própria necessidade das atividades escolares. No entanto, ao observar o gênero escolhido, pode-se inferir que os alunos DI escolhem por gêneros que demandam um menor tempo de dedicação à leitura, uma vez que a maior percentagem desse grupo escolhe a leitura de piadas e propagandas $(21 \%)$ e histórias em quadrinhos (36\%) enquanto o grupo com DS se dedica mais à leitura de romances e Literatura infantil (37\%). Aqui os principais livros apontados foram: Diário de um banana; Uma menina nada popular; A culpa é das estrelas e Naruto. Pensando nessa questão, talvez a escolha do gênero possa também estar associada à dificuldade na leitura. É claro que não se pode afirmar isso, mas isso pode ser inferido, uma vez que os alunos DI apresentam, em seu histórico, dificuldade na disciplina de Língua Portuguesa.

De acordo com Guedes e Souza (2011), para o aluno ter melhor desempenho na Língua Portuguesa, é necessário ensinar os mesmos a serem capazes de entender os textos que leem. Retomando os documentos oficiais, a exemplo das Orientações Curriculares do Estado de São Paulo (2008) e das Proposições de Expectativas de Aprendizagem para o Ensino Fundamental Ciclo I (SÃO PAULO, 2007), observa-se que, para os alunos do $5^{\circ}$. ano, é esperada uma trajetória de leitura que compreende desde o contato com receitas, listas, 
cartas, cantiga, bilhete, poema, parlenda, manchete, entrevista, reportagem, fábula, lenda, artigo de divulgação científica, notícia, reportagem, mito até a leitura de cordel, roteiro e mapa de localização/descrição de itinerário. Postas estas considerações e voltando para os resultados, percebe-se que os alunos apontam um repertório limitado de leitura, com destaque para o livro didático. Isso nos leva a verificar outra categoria de análise, referente a sua motivação, significado e frequência da leitura.

Ao questionar sobre quais as motivações que conduzem os estudantes a ler, verifica-se que, para o grupo DS, a motivação surge de uma necessidade espontânea, pelo prazer $(42 \%)$ e para se ter maior conhecimento e aprender melhor (37\%), enquanto, para o grupo DI, a exigência da escola (64\%) é o que direciona a leitura, seguida da necessidade de conhecimento e de aprendizagem de conteúdos (22\%). Apenas para 14\% do grupo DI, a leitura surge como uma necessidade individual, uma vontade intrínseca. Comparando esses resultados com a questão do significado que a leitura tem para os alunos, observa-se também diferenças entre os grupos, o que possibilita inferir que a fluência na leitura pode configurar um fator que influencia sua realização.

O significado da leitura está vinculado para ambos os grupos como importante fonte de conhecimento. Ao comparar os alunos em função do desempenho, constata-se que o grupo DS evidencia maior gosto pela leitura (63\%), afirmando que ler é uma forma de divertimento e prazer, enquanto $79 \%$ do grupo DI afirma que ler exige esforço para poder aprender e configura uma obrigação escolar, uma atividade entediante e não um deleite (79\%). Entende-se que esse resultado pode ser consequência da dificuldade dos estudantes em ler e escrever, uma vez que eles apresentam desempenho abaixo do esperado, sobretudo na disciplina de Língua Portuguesa.

Em relação à frequência de leitura de livros, $25 \%$ do grupo DS e $9 \%$ do grupo DI afirmam ler mais de cinco livros por ano, no entanto $25 \%$ DS e $58 \%$ DI leem em média apenas um livro anualmente. Claro que a quantificação não implica diretamente em melhor ou pior desempenho, entretanto alguns autores (GONTIJO, 2014; MORAIS, 2012; FRADE, 2010; Mendonça e Aranha, 2009) afirmam a importância da leitura como forma de desenvolvimento da autonomia intelectual e para o processo de aquisição da leitura e da escrita, o que tem implicações para o desempenho na disciplina de Língua Portuguesa e nas demais disciplinas.

Considerando que, ao longo de todas as séries do Ensino Fundamental, é esperado que os alunos construam um amplo repertório de leitura, conforme posto nos documentos oficiais aqui apresentados e baseando-nos nos dados exibidos na Pesquisa Retratos da Leitura no Brasil (2020), consideramos que esse grupo de estudantes está finalizando o primeiro ciclo do Ensino Fundamental com um repertório limitado de leitura e com pouca familiaridade com ela, enquanto atividade cotidiana da vida. Com base nisso, buscou-se verificar, junto ao grupo, quem são os adultos modelos leitores, qual a frequência de leitura na escola e os demais suportes de leitura, como demonstrado no Quadro 2. 
Quadro 2 - Modelo leitor.

\begin{tabular}{|c|c|c|}
\hline Categorias & $\begin{array}{ll}\text { DS } & \text { Alunos } \\
\end{array}$ & $\mathrm{D}(\%)$ \\
\hline Modelo leitor: & & \\
\hline Mãe & 61 & 64 \\
\hline Pai & 18 & 06 \\
\hline Professor (a) & 14 & 21 \\
\hline Outra pessoa & 07 & 09 \\
\hline \multicolumn{3}{|l|}{ Frequência de leitura na escola: } \\
\hline Leitura de livros/textos & 26 & 09 \\
\hline Leitura de atividades & 65 & 83 \\
\hline Atividades na biblioteca & 09 & 08 \\
\hline Outros materiais (suporte) lidos: & 67 & 65 \\
\hline Internet & 31 & \\
\hline Textos didáticos (escolares) & & \\
\hline Livros digitais / outros & 02 & 35 \\
\hline & & 00 \\
\hline
\end{tabular}

Fonte: Dados da pesquisa.

É interessante ressaltar que, para ambos os grupos, a mãe constitui o modelo leitor de referência (61\% para DS e 64\% para DI). Quando observamos o segundo leitor de referência, identifica-se uma pequena mudança: para o grupo DS, o pai é o segundo leitor (18\%) e, depois, a professora (14\%). No grupo DI, a professora é o segundo modelo (21\%), seguida por outra pessoa $(9 \%)$, sendo o pai $(6 \%)$ o último modelo adulto leitor. Ou seja, para o grupo DS, o pai e a professora são modelos leitores secundários, quando comparados a mãe. No grupo DS, o modelo secundário é a professora. A categoria outra pessoa para ambos os grupos corresponde ao líder religioso ou a um amigo próximo.

Ao detalhar qual a frequência que os estudantes observaram essas pessoas lendo, verificou-se que a mãe realiza leitura todo dia (aqui foi apontado desde revistas sobre novelas e artistas, Bíblia, folhetos de ofertas e promoções em supermercados, folheto do Avon e o horóscopo), enquanto o pai, quando visto lendo, sua leitura é relativa ao jornal entregue em semáforo. Cabe também destacar que os resultados aqui apresentados se assemelham à Pesquisa Retratos da Leitura no Brasil (2020), que identificou que o índice de leitura do brasileiro ainda é baixo, e que são as mulheres que melhor representam a população leitora.

Pode-se identificar que, em relação aos grupos, os alunos com DS têm maior referência de leitura em casa (79\%), pois os pais são modelos leitores, quando comparamos com o grupo DI, que percebe a mãe e a professora como principal modelo leitor. Não podemos 
afirmar, mas inferir, que talvez o fato de ter acesso em casa a diferentes fontes de leitura, assim como observar um membro da família lendo com frequência, pode ser um fator que contribui para uma maior autonomia e desenvolvimento não apenas da leitura em si, mas também da articulação do pensamento, da escrita e do raciocínio, o que implica no desempenho escolar e no interesse pela leitura, o que reforça o papel da escola como local para o incentivo da leitura junto aos estudantes.

A professora da sala se configura como modelo de leitura para os dois grupos (14\% DS e $21 \%$ DI), exclusivamente para leitura de atividades, tais como explicar o que deverá ser feito em sala e ao ler recados que devem ser repassados aos pais. Os alunos afirmaram que não é realizada leitura de livro ou história no $5^{\circ}$. ano pelo professor, que isso ocorria nas séries anteriores, quando eles estavam no início do Ensino Fundamental. Não podemos generalizar, mas, para esse grupo específico, observa-se que o professor regente, de acordo com a percepção dos estudantes, não tem uma rotina de leitura, o que contradiz as orientações curriculares previstas na Base Nacional Curricular Nacional (2018) e Orientações Curriculares do Estado de São Paulo (2008) e as orientações de alguns autores, como, por exemplo, Farias e Bortolanza (2012), que afirmam a importância da leitura pelo professor na prática da sala de aula como fator que influencia a formação leitora dos alunos.

No entanto, esse resultado é similar ao encontrado por Morais (2012), que, a partir do acompanhamento em 12 salas de aula de três redes públicas municipais do Estado de Pernambuco, constatou um ensino de compreensão leitora tão escasso e pouco eficiente, isso porque as professoras não faziam leitura com os alunos. O referido autor ainda destaca que foram raros os dias letivos em que, após a leitura de um texto, os alunos realizaram algum tipo de atividade de compreensão leitora. Não queremos, com essa assertiva, culpabilizar o professor da sala, que isso fique bem claro, mas podemos inferir que a mediação do professor é essencial. E, em se tratando da leitura em um grupo de alunos que não tem repertório leitor familiar, é a escola, representada pela figura do professor, que poderá tornar a leitura um elemento da rotina do estudante, não na situação limitada de cumprir tarefas, mas em descobrir a leitura como fonte de conhecimento, prazer e cultura.

Quando perguntados a respeito da leitura propiciada pela escola, os grupos se assemelham muito nas respostas. A leitura feita pela professora é realizada com frequência para a leitura de enunciados ou para a explicação de tarefas, e os dois grupos afirmam que raramente é feita a leitura de um livro ou capítulo de uma história. Também foram perguntados a respeito dos gêneros trabalhados em sala, ambos garantem que até hoje não tiveram contato com e-mail, diagrama, artigo de divulgação científica, canção e relato de experiências vividas.

Segundo os alunos, o que mais eles estudaram em termos de gêneros diz respeito a: bilhete, legenda, conto, poema, reportagem, fábula, cordel e notícia. Sobre a biblioteca, os alunos disseram raramente a frequentar, que não há um momento específico na rotina para irem procurar livros, ou fazer alguma atividade nesse espaço. A biblioteca é mais um local para ir quando o aluno está fora da sala por conta de seu comportamento ou pelo próprio interesse do aluno durante o intervalo ou após o fim da aula. E, ao verificar quais materiais os estudantes mais recorrem para leitura, os grupos se assemelham por realizar leituras na internet e de textos escolares (livros didáticos). Aqui, apenas uma pequena diferença: $2 \%$ 
do grupo DS diz já ter feito leitura de livros digitais. Pensando que essa questão acerca dos materiais lidos pelos estudantes possa estar associada à dificuldade na leitura, buscou-se conhecer como os alunos avaliam a sua própria leitura. Cabe, entretanto, enfatizar que ambos os grupos admitem que preferem acessar as redes sociais ao invés de ler um livro e que, atualmente, as redes sociais são fonte de leitura cotidiana, mas uma leitura direcionada a notícias breves e a comentários em perfis sociais.

Quadro 3 - Percepção do aluno enquanto leitor.

\begin{tabular}{l|l|l}
\hline \multicolumn{2}{c}{ Categorias } & \multicolumn{2}{c}{ DS (\%) } & \multicolumn{1}{c}{ DI (\%) } \\
\cline { 2 - 3 } & 00 & 13 \\
Não compreendo o que leio & 08 & 16 \\
Tenho dificuldade para ler & 10 & 63 \\
Leio muito devagar & 82 & 05 \\
Minha leitura é fluente & 00 & 03 \\
Não sei ler & & \\
\end{tabular}

Fonte: Dados da pesquisa.

Essa categoria representa a maior discrepância entre os grupos. No grupo DS não temos alunos que afirmem não saber ler nem que tenham dificuldades para compreender a leitura. Nesse grupo, a maior parte dos alunos, $82 \%$, considera sua leitura fluente, e apenas $8 \%$ afirmam que têm dificuldade para ler ou que leem muito devagar ( $10 \%)$. No grupo DI, temos alunos que assumem que ainda não sabem ler (3\%). Segundo a escola, esses estudantes apresentam muitas dificuldades em todas as disciplinas em razão de ainda não estarem plenamente alfabetizados. Ainda temos, nesse grupo, uma parte significativa (63\%) que assevera que sua leitura é lenta e isso atrapalha a compreensão do texto, também declara que não compreende a leitura (13\%), que tem dificuldade para ler (16\%) e apenas $5 \%$ se avaliam como leitores fluentes.

De acordo com Farias e Bortolanza (2012), ler é um processo dinâmico que implica apreender significados e também trazer para o texto lido a experiência. Afirmam ainda que a leitura é fundamental em qualquer nível e, nesse sentido, a escola deve configurar espaço de leitura e de formação de leitores. No entanto, para que isso ocorra, faz-se necessário que a escola esteja atenta às experiências de leitura de seus alunos, construídas ao longo de sua escolaridade e de sua vida. Nessa perspectiva, reiteramos aqui a importância de conhecer o contexto leitor de nossos alunos e do trabalho com leitura realizado pela escola.

\section{CONSIDERAÇões FINAIS}

Esta pesquisa procurou conhecer a relação entre a leitura e sua possível relação com o desempenho escolar de alunos do Ensino Fundamental. Foram analisados quais gêneros textuais os alunos estão lendo, quais pessoas configuram o principal modelo leitor e qual a frequência de leitura. De forma geral, pode-se afirmar que há diferenças entre os grupos e a 
análise possibilita inferir que essas diferenças podem ser causa da dificuldade do aluno em ler, da fluência de sua leitura, bem como, ser influenciada pelos modelos leitores com os quais ele convive, o que reflete diretamente em seu desempenho escolar.

O grupo com desempenho insatisfatório $(79 \%)$ considera que a leitura se apresenta como uma atividade que exige esforço, o que pode ser interpretado como um fator que implica o não gosto pela leitura. Nesse grupo, apenas $9 \%$ consideram ler uma fonte de prazer, uma atividade que agrega conhecimento e possibilita desenvolver várias habilidades. Aqui, os estudantes vincularam a leitura como uma obrigação escolar, dizendo que ler, muitas vezes, representa uma atividade entediante, sem sentido específico e uma exigência para a realização de tarefas. Entende-se que esse resultado pode ser consequência da dificuldade de os estudantes em ler e escrever, uma vez que eles apresentam desempenho abaixo do esperado, sobretudo na disciplina de Língua Portuguesa.

Por sua vez, esse resultado preocupa por duas razões. A primeira é o fato de os estudantes terem dificuldade para ler estando no $5^{\circ}$. ano do Ensino Fundamental, o que agrava sua precária situação escolar, uma vez que esse grupo é apresentado pela escola como alunos de baixo rendimento. A segunda é porque isso também sinaliza que a escola não está conseguindo reverter essa relação com a leitura, ou seja, não está conseguindo transformar essa percepção de que ler é uma atividade tediosa ou difícil.

Assim, acredita-se que se mantém um círculo vicioso e perverso, em que aqueles que têm uma relação mais positiva com a leitura progridem na escola e continuam tendo inúmeras possibilidades de acesso aos diferentes gêneros e materiais textuais, enquanto os alunos que têm dificuldade para ler mantêm uma relação negativa com a leitura, e são talvez impossibilitados de terem oportunidade para modificar essa percepção, o que mantém seu distanciamento com a leitura e, de certa forma, reforça seu desempenho abaixo do esperado. Não está se responsabilizando a escola, mas apontando que, ao se considerar a leitura como primordial ao desenvolvimento da autonomia e para a construção da cidadania, então é preciso pensar em possibilidades e em formas didáticas de tornar a leitura uma atividade cotidiana na escola. Essa cotidianidade não deve ser exaustiva e afastar os alunos, mas uma atividade que agregue conhecimentos e desenvolva a consciência da importância da leitura e sua finalidade para a escolarização, para a vida e para o próprio aluno. Isso posto, uma questão aparece: quais leituras estão sendo realizadas na escola e quais textos os alunos estão lendo?

Os relatos dos estudantes evidenciam que, apesar de os programas oficiais claramente definirem que, na disciplina de Língua Portuguesa, serão proporcionados aos estudantes o contato com uma extensa variedade textual que inclui desde parlendas, literatura infantil até textos científicos, englobando as diferentes esferas de circulação de textos (cotidiana, escolar, jornalística e literária), isso, na prática, não está ocorrendo. Os alunos argumentaram que, mesmo estando no final do $5^{\circ}$. ano, ainda não entraram em contato com alguns gêneros textuais e que não há, em sala de aula, para esse grupo, uma atividade cotidiana de leitura feita pelo professor, leitura essa que não seja a de um enunciado de exercício ou do texto para interpretar. Parte-se do pressuposto de que a leitura cotidiana é primordial para a construção de conhecimento, para a motivação da leitura e para a organização de ideias e para o desenvolvimento da linguagem. Acredita-se que cabe, então, à instituição escolar rever as práticas que estão sendo mantidas, a fim de facilitar a aprendizagem dos alunos e efetivamente propiciar a leitura como fruição. 
É preocupante verificar que $25 \%$ dos alunos com satisfatório desempenho e $58 \%$ com insatisfatório leem em média apenas um livro por ano e que a escola não está sendo um modelo leitor, representada aqui pelo professor, nem proporcionando atividades dirigidas à leitura na biblioteca, por exemplo. Em relação ao tipo de leitura, percebe-se que os livros didáticos são lidos por ambos os grupos, muito em decorrência da própria necessidade das atividades escolares. No entanto, os alunos DI escolhem por gêneros que demandam um menor tempo de dedicação à leitura, uma vez que a maior percentagem desse grupo escolhe a leitura de histórias em quadrinhos, enquanto o grupo com DS se dedica mais à leitura de romances e Literatura Infantil. Que fique registrado que não se está priorizando qualquer gênero textual em detrimento do outro, apenas apontando para essa questão, pois, aqui, isso parece um importante dado de pesquisa e que reflete na opção do leitor que tem maior ou menor dificuldade com a leitura.

Quando se verificam os modelos que esses estudantes têm como referência, para ambos os grupos, a mãe constitui o maior modelo leitor e sua leitura é normalmente dirigida a revistas de fofoca, encartes de produtos de beleza e folhetos do mercado. Isso reflete o quanto a família também influencia esses alunos. A professora aparece como segundo modelo, mas, como exposto pelos alunos, a leitura realizada em sala de aula se dirige mais para atividades específicas, exercícios, recados e conteúdos formais, não aparecendo, para esse grupo, como uma atividade que envolva a diversidade de gêneros textuais.

Ao investigar as motivações que conduzem os estudantes a realizar a leitura, também há diferenças, o que novamente possibilita inferir que a fluência na leitura pode influenciar o estudante a ler e a repercutir em seu desempenho. Para o grupo DS, a motivação para a leitura surge de uma necessidade espontânea, pelo prazer de ler e para se ter maior conhecimento, ficando a exigência da escola como menos significativa. No grupo DI, a exigência da escola é o que direciona a leitura, seguida da necessidade de conhecimento e de atualização, sendo, para um menor número de estudantes, a leitura como uma necessidade individual, uma vontade pessoal.

Acredita-se que estes dados servem como um possível indicador de práticas que estão sendo mantidas na escola, e que refletem a disparidade entre o que se pretende fazer (documentado em programas oficiais) e aquilo que realmente é realizado. Esta pesquisa reflete uma pequena realidade, no entanto acredita-se que essa possa ser encontrada em muitas outras escolas. Tais dados permitem afirmar sobre a importância do incentivo à leitura como uma atividade planejada e direcionada pelo professor em sua rotina diária, bem como a inserção de diferentes gêneros textuais e a utilização de diversos suportes midiáticos.

As limitações dizem respeito a se ter realizado entrevista apenas com alunos e não se ter confrontado, junto aos seus professores, como a leitura está sendo trabalhada em sala de aula, quais são os gêneros mais lidos e com que frequência. No entanto, acredita-se que esta pesquisa abre a possibilidade de investigação com a leitura na escola, ou seja, analisar, junto aos professores e à equipe gestora, quais as práticas cotidianas com a leitura e investigar como a escola trabalha e promove a leitura, incluindo aqui o uso da biblioteca. Considera-se que este trabalho irá contribuir para a reflexão de professores em exercício, gestores e futuros docentes para novas formas de se conceber e organizar a leitura na escola. 


\section{REFERÊNCIAS}

BATISTA, Antonio Augusto Gomes et al. Capacidades linguísticas: alfabetização e letramento. In: BRASIL. Pró-letramento: programa de formação continuada de professores dos anos/séries iniciais do ensino fundamental: alfabetização e linguagem. Brasília: Ministério da Educação: Secretaria de Educação Básica, n. 1, p. 3-60, 2012.

BAPTISTA, Monica Correia. Alfabetização e letramento em classes de crianças menores de sete anos. In: FRADE, C.A.S. (org.). Convergências e tensões no campo da formação e do trabalho docente. Belo Horizonte: Autêntica, 2010.

BRASIL. Base Nacional Comum Curricular (BNCC). Consulta Pública. Brasília: MEC/ CONSED/UNDIME, 2015c. Disponível em: http:/historiadabncc.mec.gov.br/documentos/BNCC-APRESENTACAO.pdf . Acesso em: 25 jul. 2018.

. Secretaria de Educação Básica. Diretoria de Apoio à Gestão Educacional. Pacto nacional pela alfabetização na idade certa. Ministério da Educação, Secretaria de Educação Básica, Diretoria de Apoio à Gestão Educacional. Brasília: MEC, SEB, 2012, 47p.

. Secretaria de Educação Básica. Diretoria de Apoio à Gestão Educacional. Pacto nacional pela alfabetização na idade certa: a apropriação do sistema de escrita alfabética e a consolidação do processo de alfabetização: ano 2: unidade 3 / Ministério da Educação, Secretaria de Educação Básica, Diretoria de Apoio à Gestão Educacional. Brasília: MEC, SEB, 2012, 48 p.

. Retratos da leitura no Brasil. Disponível em: < http://www.brasil.gov.br/cultura/2015/07/retratos-da-leitura-no-brasil/view>. Acesso em: 6 set. 2015.

DIÁRIO OFICIAL DA UNIÃO. DECRETO No .9 .765 , DE 11 DE ABRIL DE 2019 - Institui a Política Nacional de Alfabetização. Publicado em: 11/04/2019 | Edição: 70-A | Seção: 1 - Extra | Página: 15.

FAILLA, Zoara. (org.). Retratos da leitura no Brasil $5^{\text {a }}$ edição. Instituto Pró-livro (IPL), IBOPE, 2020. Disponível em: http://plataforma.prolivro.org.br/retratos.php. Disponível em: 23 nov. 2020.

FARIAS, SANDRA ALVES.; BORTOLANZA, ANA MARIA ESTEVES. O papel da leitura na formação do professor: concepções, práticas e perspectivas. Poíesis Pedagógica, v.10, n. 2, p. 32-46, 2012.

FRADE, Isabel Cristina Alves da Silva. Métodos de alfabetização, métodos de ensino e conteúdos da alfabetização: perspectivas históricas e desafios atuais. Educação, Santa Maria, v. 32, n. 01, p. 21-40, nov. 2007. Disponível em: http://cascavel.ufsm.br/revistas/ 
ojs-2.2.2/index.php/reveducacao/article/viewFile/658/469cascavel.ufsm.br. Acesso em: 10 fev. 2015.

FRADE, Isabel Cristina Alves da Silva (org.). Convergências e tensões no campo da formação e do trabalho docente. Belo Horizonte: Autêntica, 2010.

GONTIJO, Claudia Maria Mendes. Alfabetização: políticas mundiais e movimentos nacionais. Campinas, SP: Autores Associados, 2014.

GUEDES, P. C.; SOUZA, J. M. Introdução: leitura e escrita são tarefas da escola e não só do professor de Português. In: NEVES, I. C. B. et al. Ler e escrever: compromisso de todas as áreas, 3. ed. Porto Alegre: Ed. da UFRGS/Faculdade de Arquitetura, 2011, p. 13-18.

INSTITUTO NACIONAL DE ESTUDOS E PESQUISAS EDUCACIONAIS ANISIO TEIXEIRA - INEP. Sistema Nacional de Avaliação da Educação Básica - SAEB, 2019. Disponível em: https://www.gov.br/inep/pt-br/assuntos/noticias/saeb/divulgados-resultados-amostrais-do-saeb-2019. Acesso em: 23 nov. 2020.

. Sistema Nacional de Avaliação da Educação Básica - SAEB, 2017. Disponível em: http://portal.inep.gov.br/educacao-basica/saeb/resultados. Acesso em: 23 nov. 2020.

. Prova Brasil, 2015. Disponível em: http://portal.inep.gov.br/artigo/-/asset_publisher/B4AQV9zFY7Bv/content/inep-apresenta-resultados-do-saeb-prova-brasil-2015/21206>. Acesso em: 23 nov. 2020.

. Saeb 2017 revela que apenas 1,6\% dos estudantes brasileiros do Ensino Médio demonstraram níveis de aprendizagem considerados adequados em Língua Portuguesa. Disponível em: <http://www.inep.gov.br>. Acesso em: 25 nov. 2020.

KISHIMOTO, Tizuko Morchida. Alfabetização e letramento/literacia no contexto da educação infantil: desafios para o ensino, para a pesquisa e para a formação. In: FRADE, Isabel Cristina Alves da Silva. (org.). Convergências e tensões no campo da formação e do trabalho docente. Belo Horizonte: Autêntica, 2010.

KOCH, Ingedore Vilhaça; ELIAS, Vanda Maria. Ler e compreender: os sentidos do texto. SP: Contexto, 2014.

KRAMER, Sonia. O papel da educação infantil na formação do leitor: descompassos entre políticas, as práticas e a produção acadêmica. In: FRADE, C.A.S. (org.). Convergências e tensões no campo da formação e do trabalho docente. Belo Horizonte: Autêntica, 2010.

LAJOLO, Marisa; ZILBERMAN, Regina. Um Brasil para Crianças: Para conhecer a Literatura Infantil brasileira: Histórias, autores e textos. São Paulo: Global, 1986. 
LEITE, Sergio Antonio da Silva. Afetividade e letramento na alfabetização de adultos. São Paulo: Cortez, 2013.

MENDONÇA, Martha., ARANHA, Ana. No sexto ano da escola, eles não sabem escrever. Revista Época. Publicado em 20/03/2009. Disponível em: <http://revistaepoca.globo. com/Revista/Epoca/0,EMI64896-15223,00.htm>. Acesso em: 9 out. 2015.

MORAIS, A. G. de. Por que defendemos um ensino sistemático da escrita alfabética? In: BRASIL, Pacto Nacional pela Alfabetização na Idade Certa. A oralidade, a leitura e a escrita no ciclo de alfabetização. Caderno 05 / Ministério da Educação, Secretaria de Educação Básica, Diretoria de Apoio à Gestão Educacional. Brasília: MEC, SEB, 2015, p. 59-67.

MORAIS, Arthur Gomes. Políticas de alfabetização: discutindo a Provinha Brasil. Revista Brasileira de Educação, v. 17, n. 51, 2012.

NEVES, Iara, Conceição Bitencourt, SOUZA, Jusamara Vieira, SCHÄFFER, Neiva Otero, GUEDES, Paulo Coimbra, KLÜSEMER, Renita (orgs.). Ler e escrever: compromisso de todas as áreas. Porto Alegre: Editora UFRGS, 2011.

PRÓ-LETRAMENTO: Programa de Formação Continuada de Professores dos anos/ séries iniciais do Ensino Fundamental: alfabetização e linguagem. Secretaria de Educação Básica. Brasília: Ministério da Educação, 2008.

SALES, Irailde Almeida. Leitura e escrita nos ensinos fundamental e médio: refletindo e exercitando possibilidades. In: VARANI, Adriana, FERREIRA, Claudia Roberta, VAL TOLEDO, Guilherme Prado. Narrativas docentes: trajetórias e trabalhos pedagógicos. Campinas, SP: Mercado das Letras, 2007.

SANTOS, P. S. A redação nas séries finais do ensino fundamental: da análise de erros às estratégias didáticas, 2015, 218s. Tese (Doutorado) - Curso de Pós-graduação em Linguística, Português e Línguas Clássicas, Instituto de Letras - Universidade de Brasília, Brasília, 2015. Disponível em: http://repositorio.unb.br/bitstream/10482/19178/1/2015 PriscillaSilvaSantos.pdf. Acesso em: 2 jul. 2017.

SÃO PAULO. Avaliação da aprendizagem em processo: Subsídios para o Professor de Língua Portuguesa. Comentários e Recomendações Pedagógicas. São Paulo: Primeiro Semestre de 2014.

. Expectativas de aprendizagem de Língua Portuguesa dos anos iniciais do Ensino Fundamental $-1^{\circ}$. ao $5^{\circ}$. ano. São Paulo: Coordenadoria de Gestão da Educação Básica, 2013. 
. Orientações Didáticas fundamentais sobre as expectativas de aprendizagem de Língua Portuguesa. São Paulo: Coordenadoria de Gestão da Educação Básica, 2013.

. Orientações curriculares do Estado de São Paulo: Língua Portuguesa e Matemática - ciclo I. Secretaria da Educação. São Paulo: FDE, 2008, p. 7-22.

SFORNI, M. S. F.; GALUCH, M. T. B. Conteúdos escolares e desenvolvimento humano: qual a unidade? Comunicações. Revista do Programa de Pós-graduação em Educação UNIMEP. Ano 13, nº. 2, p. 150-158, 2006.

SOARES, Magda. Letramento e Alfabetização: as muitas facetas. Revista Brasileira de Educação, 2004, p. 5-17.

. Letramento: um tema em três gêneros, 2. ed. Belo Horizonte: Autêntica, 2006.

. SOARES, M. Alfabetização: a questão dos métodos. São Paulo: Contexto, 2016.

VIEIRA, Adriana Silene; FERNANDES, Célia Regina Delácio, SILVA, Márcia Cabral da, MARTINS, Milena Ribeiro. Organização e uso da biblioteca escolar e das salas de leitura. In: PRÓ-LETRAMENTO: Programa de Formação Continuada de Professores dos anos/séries iniciais do Ensino Fundamental: alfabetização e linguagem. Secretaria de Educação Básica. Brasília: Ministério da Educação, Fascículo 4, 2008.

\section{DAdOS DA AUTORA:}

\section{Andreia Osti}

Doutora em Educação pela Universidade de Campinas. Campinas/SP-Brasil. Professora do Programa de Pós-Graduação em Educação da Universidade Estadual Paulista "Júlio de Mesquita Filho". Rio Claro/SP-Brasil. andreia.osti@unesp.br

Submetido em: 10-5-2019

Aceito em: 1-12-2020 